\title{
Recent Advances in Intelligent-Based Structural Health Monitoring of Civil Structures
}

\author{
Satyam Paul ${ }^{*}$, , Raheleh Jafari ${ }^{2}$ \\ ${ }^{1}$ School of Engineering and Sciences, Tecnologico de Monterrey, Monterrey, Nuevo Leon, 64849, Mexico \\ ${ }^{2}$ Centre for Artificial Intelligence Research (CAIR), University of Agder, Grimstad, 4879, Norway
}

\begin{tabular}{l} 
A R T I C L E I N F O \\
\hline Article history: \\
Received: 16 August, 2018 \\
Accepted: 10 October, 2018 \\
Online: 18 October, 2018 \\
\hline Keywords: \\
Structural health monitoring \\
Damage detection \\
Civil structures \\
Intelligent techniques \\
\hline
\end{tabular}

\section{Introduction and Preliminary Concepts}

The main intention of structural health monitoring methodology is to the expose of the area of damage and then to evaluate its location and severity thus predicting the life. Visual inspection and experimental measurement techniques are an important aspect of damage detection methodology. More and more research on the field of global detection methods in the identification of damages in the structure during and aftermath of seismic events has resulted in the investigation of methodology used in mechanical, nuclear, and aerospace engineering [1,2]. The civil engineering structures like multistory buildings, towers and bridges tend to damage gradually with time elapse or due to sudden environmental disasters. So structural health monitoring is an important area of research that verifies the safety of civil structures from various issues. The stability and reliability of civil structure becomes a matter of concern after a strong earthquake and so more and more studies are carried on structural damage detection using different nondestructive computation methods. The vibration techniques are another popular method to identify the location of the damages with accuracy and thus considered to be global technique. The vibration methods associated with structural health monitoring detects the changes in the modal properties of the structure.

The constraints associated with these techniques are: a) the influence of factors producing same to same effects on the evaluation parameters which are not easy segregate, b) civil

*Satyam Paul, Monterrey, Mexico, satyam.controlsystems@gmail.com engineering structures has superfluity that give rise to low sensitivity of the method in case of localized damaged, c) the uncertainties in the model, d) the noises in the measurements, e) in case of training data, uncertainties may incorporated in the data due to adverse conditions and d) in case of artificial neural networks, there is completeness of the conceived damage scenarios and training data sets $[3,6]$. The method of damage detection of civil structures using non-destructive techniques (NDE) is an area of interest among the researchers. Its applications extents from aviation industries, manufacturing techniques, space shuttles, architectural industry, devices related to power plants, etc. The damage detection in structures cab be subdivided into local and global techniques. The local methodology are mainly applied for tiny and generalized structures for example pressurized vessels. The limitation of damage identification method involving local concepts is that it fails to detect the damages in case of large and complicated structures. In case of onsite structural damage detection, engineers can apply local detection method only to investigate some special component of the structures. The analysis of entire structure including some large and complicated structure is possible through global vibration-based identification of damages in structure $[7,8]$. The variation in the parameters of structural modal is considered to be an early signal of the occurrence of damage in the structures [9]. The validation of reliability in function of numerous crucial technical structures by tracking online and detection of damage in continuous mode is possible using vibration based methodology. As a result of which vibration based method is growing area of interest among the 


\section{S. Paul et al. / Advances in Science, Technology and Engineering Systems Journal Vol. 3, No. 5, 339-353 (2018)}

researchers. The main concept of vibration based damage detection is that the changes associated with the physical properties like mass, damping and stiffness will result in a change in the modal properties like natural frequency, modal damping and mode shapes. The past three decades have witnessed the contribution of the researchers in all three domains of time, frequency and modal domains. The effort of the researchers in this field will continue as existing methods cannot rectify all the damages that is incorporated in the structures [10]. In [11], the author has broadly distinguished between various methods on the basis of the level of identification attempted as shown in Table 1:

Table 1: Level of identification

\begin{tabular}{|c|c|}
\hline Level & \multicolumn{1}{|c|}{ Various Methodology } \\
\hline 1 & To determine that the damage exists in the structure \\
\hline 2 & To determine the damage geometric location \\
\hline 3 & To estimate the level of extent of damage \\
\hline 4 & To forecast the remaining life of the structure \\
\hline
\end{tabular}

Vibration-based structural damage detection can be broadly classified into traditional and modern type which is still under development and innovation. The description and comparison of traditional method and modern methods have been vividly described in forthcoming sections. The modern-type methods of structural health monitoring can be classified as wavelet analysis, fuzzy logic concept, neural network techniques, genetic algorithm methodology. In this paper, the intelligent technique related to structural monitoring techniques are discussed and analyzed. The intelligent methodologies can sub divided as neural network techniques, Fuzzy logic theory, concept of genetic algorithm and hybrid intelligent techniques. The researchers are taking lot of interest in the optimization methodology involving genetic algorithms [12] and neural networks [13] in order to investigate localized damage variation as a function of modal data. In the area of research associated to civil structures to the optimization of structure[14] as well as scheme related to the identification of structure [15] there has vast use of genetic algorithm for handling optimization problems. The detection of structural damages using this methodology is growing vastly. The synergistic combination of algorithms associated with Eigen sensitivity and genetic algorithm for optimizing the discrete variables of damage area as well as their extent utilizing natural frequencies is illustrated by [16]. The methodology of genetic algorithm in the detection of structural damages was presented by [17]. They utilized optimization fitness function techniques associated to displacements which is static in nature. Good linear mapping capability, inverse problems solving ability and high degree of robustness is the criteria of artificial neural network that makes it an important methodology in the field of structural health monitoring and detection. Several investigators utilized artificial neural network for the detection of localize as well as to compute the damage involved. The popular type of neural network termed as multi-layer perception (MLP) is utilized in health monitoring of structures as well as well in the situations involving identification $[18,20]$. In the area of fault diagnosis and structural damage detection, there is a wide popularity of fuzzy logic for its embedded abilities in extracting precise and reliable data from imprecise as well as uncertainty features [21, 22]. Fuzzy logic has been employed in wide areas of fault diagnosis and structural damage detection and is a growing area of interest. The developed fuzzification technology associated with fuzzy concept is counted for uncertain factors as well as the methodology of training approaches is uncounted in numerable phase involving noisy determinants in comparison to the neural approaches for accounting of uncertainty [23]. In [24], the authors demonstrated a concept to evaluate structural damage utilizing vibration data as well as fuzzy clustering. A novel methodology was demonstrated by [25] which is a combination of fuzzy logic, neural network and wavelet transformation for the detection of damages in structures. Researchers are taking widespread interests in the field of structural health monitoring that uses combined intelligent methodologies. In [26], the authors utilized a fuzzy-neuro hybrid technique to monitor the health condition of bridges. The decision system of fuzzy logic utilizes fuzzy clustering methodology in order to determine the damages in the bridge. A neural network forecasting technology makes use of back propagation algorithm to predict the correct amount of damage. An innovative filter design on the basis of combined neural and genetic algorithm concept for the improvisation health monitoring technique was proposed by [27].

In the next section, focused is vested on the traditional techniques associated to structural health monitoring. This section is followed by a modern methodology involved in health monitoring od structures which is followed by a brief overview of wireless sensors and then detailed analysis on intelligent techniques are illustrated. Finally conclusion is provided to give an overview of the paper.

\section{Methods based on traditional techniques}

The conventional methodology for the detection of damages in structure utilizes the mechanical approaches related to the structural attributes. The methodology involved in this type of techniques are transfer function computation or experimental modal evaluation. This techniques are not widely used in online detection of structures because the experimental data requires instruments which are diversified or involves manual operations. Therefore this technology has been not taken up with greater interest in recent studies. The main advantage of natural frequency analysis technique is that it is easily measurable in case of structures and does not depend on the measured position. Generally the preciseness of computation utilizing natural frequency methods is superior when compared with the mode shape analysis or modal damping. In [28], the authors proposed an innovative technique for extracting the information on the size and location of structural damage by utilizing the concept of natural frequency. In the current method, the location of the crack is obtained using Armon's Rank-ordering method and selecting the first four natural frequencies. In [29], the researchers proposed an innovative technique for the detection and computation of the damaged layout in structural devices utilizing a limited natural frequency. An algorithm with the properties of localized damages criteria is generated for tracking damages in terms of natural frequency variance as well as quantifying damage algorithms in order to predict the dimension of the crack. The method solely verifies the presence of large damage, but it is a matter of difficulty 


\section{S. Paul et al. / Advances in Science, Technology and Engineering Systems Journal Vol. 3, No. 5, 339-353 (2018)}

to extract the damage location due to the fact that structural damage in different location may result in same frequency alteration. The changes in natural frequency will result in detection of damages in structure but in order to access the location of structural damage, information on vibration modes is utter necessary. In [30], the authors handled the constraints associated with the extraction of damages utilizing outcome based computation of vibration in the grip of varying environmental conditions. Using the computation techniques, two variety of features are extracted categorize under Eigen properties of the structure with help of automatized stochastic identification of the subdivided space methodology as well as with the help of peak indications calculated based on Fourier transform associated with the filters related to the modal. The method of modal analysis for the research on the damages on a wooden wall was investigated by [31]. They use the technique of damage-sensitive parameters computation for the investigation. The damaged zone is detected by inspecting visually the various period of damaged states related to the deformation in mode dimensions. The analysis of modal residue as well as variations in stiffness is an requirement for superior illustration of the damaged zone. The structural vibration mode is lower when compared with the natural frequency associated with the preciseness of computation although vibration mode generate more information related to damages. The damage detection methodology based on flexibility matrix change depends on the mode shape as well as reciprocal natural frequency and also the generalized criteria is satisfied by the structural vibration mode. Hence, in flexibility matrix the high frequency element will decrease in a rapid manner with the increasing of natural frequency. In [32], the author proposed a methodology for diagnosing damage in structure on the basis of change in dynamically computed flexibility and structural stiffness. The detection of damage is not only the primary objective, the detection of location is also very much essential. The implementation of the identification methodology utilizing covariance-driven subspace gives an idea of structural modal parameters. The main idea is to extract the dimensions of the matrix that are flexible and is related to the computed DOF. The concept of pseudo inversion will yield stiffness matrix. The damage localization is extracted with combined analysis of changes in two calculated matrices considering a reference state until the damaged state. In most cases, when some damage is visible in a structure, it is convenient to extract more information from stiffness matrix than the mass matrix. The one of the properties of stiffness is that it changes in astonishing manner when major damage occurs in a structure and therefore the change of stiffness matrix can be used to detect damages. But this method fails to do justice in case the damage is very small. Non-inclusion of mathematics model, vibration mode measurement and experiential knowledge in frequency response function methods makes it an advantageous model. So this model can be used for monitoring online. In [33], the researcher proposed and developed new monitoring techniques considering higher order spectra for the frequency response functions in order to monitor involved nonlinearities in structure as well as nonGaussian types of signal in case of damage as well as the computation of related to the phase-coupling of harmonics signal associated with the structures. The proposed methodology is in general traditional functions associated to the frequency response for the investigation of spectrum for actual value transformations in higher order. A damage identification technique relied on artificial neural network in combination with frequency response functions was investigated by [34]. This technique can effectively analyze nonlinear damages suitable to some level of excitation. The important concept of their work is to illustrate a practical methodology associated to vibration dependent structural health monitoring. This innovative technique reduces the dimension of the initial frequency response function values and converts it into latest damage indices and engages technique of artificial neural network for the exposure of different level of nonlinearity with the help of damage patterns recognition. The main disadvantages of this methodology is that the quantity as well as the zone of measured point have an impact on the accuracy of structural damage detection. A newly developed concept for the identification of structural damages based on the dual methodology of instant identification of damping coefficient and wavelet transform was presented by [35]. The combination of experimental results and numerical simulations justifies that in structural systems with incorporated damages results in crucial variations in damping. Thus, the parameters linked to the structural damping can be used as sensitivity to damages associated to system properties. In [36], the authors proposed a technique where sensitivity-based finite element (FE) model updating methodology is implemented for damage detection. The optimization algorithm is utilized for the minimization of the objective function and to initiate the damage detection techniques. In [37], the authors developed a novel damage indicator termed to be as mode shape area index on the basis of mode shape changes. This developed methodology found out to be as the most sensitive damage detection approach. A statistical technique with combined uncertain frequency as well as mode shape data for the detection of damages in structure is suggested by [38]. The suggested technique is implemented to a laboratory tested steel cantilever beam and frame structure. The experimental results validate that all the damages are detected suitably with high probabilities of damage existence. The utilizing of frequency response functions for the detection of damages in structure was proposed by [39]. The suggested technique iteratively maximizes the elements related to the damages by not including the elements which were validated as undamaged from the sets of good elements. The mentioned approaches was applied to numerical simulations using a structural setup having 2D frame, also the efficiency was established. These conventional techniques have some constraints to be mention as [40]:

- Due to its dependency on experimental results to be mention as modal shape computation as well as the calculation involving damping but it incurs computation cost. This creates a negative impact on online damage detection techniques.

- In terms of damage location identification, this methodology is not popular because of its complexity to develop a recognized methodology considering several structures due to its severe dependency on the acquirement of the individual structures which are required for the detection.

- The conventional techniques fail to unearth the minute damages associated with the structures.

\section{Detection techniques based on modern methodologies}

Modernized pattern of vibration reliable structural damage detection which is also known as intelligent damage extraction 


\section{S. Paul et al. / Advances in Science, Technology and Engineering Systems Journal Vol. 3, No. 5, 339-353 (2018)}

technique is a renowned methodologies for the detection of damage utilizing online computed structural vibration responses. The methodology utilize combined technology of current signal processing concepts as well as artificial intelligence analyze mechanisms. The methods fall under this category is wavelet analysis, neural network, genetic algorithm, etc. Wavelet analysis is an upcoming research filed mainly in the area of signal processing. It has been implemented with success in many applications such as transient signal analysis, image analysis, structural health monitoring system etc. The existence of damage in structure can be identified using the spectrum graph obtained using wavelet transform. A wavelet based concept for the detection of structural damages was proposed by [41]. In their work, they illustrated the analysis of vibration signals characteristics associated with wavelet transformations. The concept is implemented to simulated data extracted from an complex structural model under the effect of harmonic excitation. The model is made up of numerous breakable springs, of few may undergo irreversible damage when the value of response exceeds the value of threshold or the number of cycles of motion is stored beyond their fatigue span.

In [42], the authors demonstrated an innovative concept on the basis of fuzzy concept involving wavelets phenomena for the identification of damages in structure. The methodology is the combination of Wavelet Packet Transform which is used for feature extraction and the capabilities of fuzzy sets to model vagueness as well as uncertainty. The operation are carried out in two steps mainly the training of pattern and the monitoring of health. The general difference illustrating the importance of each technique is given in Table 2. The elaborate explanation about the intelligent methodologies associated with structural health monitoring has been depicted vastly in this survey paper.

\section{Importance of wireless sensors for the health monitoring of structures}

The technology of wireless sensing is an important area of research preferred by the researcher in the structural health monitoring. The wireless sensing unit is designed and developed for reliable communication of response measurements as well as for power efficiency. The extraction of signals for structural health monitoring is an important step and so a short illustration of wireless sensors is provided in this section. In [43], the authors had illustrated a brief review on the experiences of the investigators working on wireless sensors as well as sensor networks for maintaining records on structural performance and health. The structural monitoring systems involving wireless technology is a popular area of research because of its positive criteria such as low cost instillation since wiring is not essential between the sensors and data acquisition device. The stated methodology plays superior roles in the processing of structural response data since it is implemented to validate data involving signs of damages associated with the structure. The analysis on results related to international cooperative analysis on smart wireless sensors was carried out by [44]. In the initial phase of this research, the concept associated with the smart wireless sensor is investigated. In the next phase, the subsystems associated to the smart wireless sensor are illustrated. Apart from that, available wireless sensor platforms manufactured in the research companies are investigated. In the final phase, three smart wireless SHM technologies were demonstrated by the investigators which has vast scope in the identification of structural damages. In [45], the reseacher developed a novel wireless sensing unit device for intelligence monitoring of remote systems. The sensor is utilized for bridge as well as infrastructure SHM. The design is carried out based on cost reduction and superior performance. In [46], the authors illustrated an innovative wireless sensing device for structural health monitoring of historic landmarks. This technique minimizes the problems connected to the wired monitoring systems. In [47], the authors illustrated a design of an innovative low powered academic wireless sensor model for the monitoring of the structure. The effectiveness of the sensor design is assured via performance analysis. In [48], the researchers suggested a wireless sensing model incorporated with multitasking capabilities using recently widely available incorporated system components.

Table 2: Comparison of methodologies

\begin{tabular}{|l|l|l|}
\hline Fuzzy Logic & Neural Network & Genetic Algorithm \\
\hline $\begin{array}{l}\text { Fuzzy logic is } \\
\text { superiorly capable } \\
\text { of handling } \\
\text { uncertainties and } \\
\text { complexities in } \\
\text { structure with ease } \\
\text { and effectively. }\end{array}$ & $\begin{array}{l}\text { In case of arbitrary } \\
\text { complex functions } \\
\text { situations, neural } \\
\text { network is } \\
\text { considered to be as } \\
\text { generalized } \\
\text { function } \\
\text { predictors. }\end{array}$ & $\begin{array}{l}\text { Genetic algorithm is } \\
\text { considered to be a } \\
\text { powerful tool when } \\
\text { implemented to solve } \\
\text { combinatorial } \\
\text { problems and so is } \\
\text { advantageous in case } \\
\text { of structural health } \\
\text { monitoring. }\end{array}$ \\
\hline $\begin{array}{l}\text { Fuzzy logic is } \\
\text { simple, easy to } \\
\text { implement and } \\
\text { robust in nature. }\end{array}$ & $\begin{array}{l}\text { Neural Network } \\
\text { has the capabilities } \\
\text { of predicting the } \\
\text { structural health } \\
\text { during the } \\
\text { operation without } \\
\text { the necessity of } \\
\text { interruption or the } \\
\text { termination of the } \\
\text { process. }\end{array}$ & $\begin{array}{l}\text { Genetic algorithm is } \\
\text { capable of } \\
\text { determining the } \\
\text { location of damage } \\
\text { more precisely and } \\
\text { computes the } \\
\text { magnitude of } \\
\text { damage more } \\
\text { significantly. }\end{array}$ \\
\hline
\end{tabular}

\section{Involvement of intelligent methodologies in structural health monitoring}

\subsection{Genetic algorithm}

Genetic algorithm (GA) is advantageous because it offers easy implementation due to the fact that only an objective function is necessary and derivatives or other supplementary details are not required. So this attributes of GA makes it strong and most trust worthy in the field of structural optimization [49, 50]. The technique of GA have been used in model updating and detection of damage by few researchers in recent studies [51]. The technique of optimization utilizing the concept of genetics which is considered to be a zone of great interest among researchers investigating on the localized damage alteration as a function of sets involving modal [52]. In [53], the author had presented a technique of real number encoded genetic algorithm which is utilized in analysis of damages in structure utilizing method of objective function minimization. On the basis of available vibration data 3 separate attributes to be mentions as frequency variation, mode dimension variation and combination of this two 


\section{S. Paul et al. / Advances in Science, Technology and Engineering Systems Journal Vol. 3, No. 5, 339-353 (2018)}

are taken into consideration. The direct collation is done by the objective function by the changes in the measured vibration extracts via damaged as well as undamaged structure before and after update. In their work, they used laboratory certified cantilever beam and frame to verify the efficiency of real-coded GA for the verification of structural damage. In [54], the researchers implemented the methodology of genetic algorithm in order to identify damages in vibrating structures. They utilized the concept of residual force matrix in combination of optimal methods for the identification of damages. The mentioned methodology is verified by the use of a doubled centered crossover dual embedded genetic algorithm complied with selected tournament for reproducing population. The optimal solution through GA is computed by utilizing $\mathrm{C}$ program for generating programs which utilizes the concept of eigenvalue forecasting code at par with sub program termed as force function residue. The methodology involves an appropriate selection of crossover as well as mutation operators. Considering the samples of 40 individuals with crossover probability 1.0 , mutation probability 0.001 , and each structural parameter $\beta_{i}$ was illustrated as a 10 bit binary number having variable limits from 0 to 1 . The main complexity involved is in obtaining the minimal force residue. Also the function related to the fitness is selected in the current matter termed to be as inverse function is illustrated as:

$$
M=\frac{C_{1}}{C_{2}+f\left(\beta_{1}, \beta_{2}, \ldots . \beta_{n}\right)}
$$

$C_{1}$ and $C_{2}$ are valued with number 1 and considered to be constants. The identification of damage parameters for various structures is done from associated residual vectors minimization problems that are handled by genetic algorithms. This technique explored the excellent bonding with those chosen for the mechanical simulation of these damaged structures. Tso and Shen [55] have used residual forced vectors in identification process based on neural network to display the properties of good location and severity assessment. In [13], the author had presented the concept of vectors associated with residual force in order to point out an objective function for a technique of optimization, which is imposed using genetic algorithm. The main intention involving the detection of structural damage is the formulation of parameters based on objective function. The formulation rules of objective function should include the process of obtaining the maximum value during the process of evaluation taking into consideration the true parameters. This is a matter of importance as the technique of optimization like the concept of genetic algorithm may be implemented to extract the parametric values using iterative methodology by choosing values for maximizing the objective function. The structural situation about the damaged states incurred can be established using the procedure of optimizing to get the solution values of the parameters. For addressing the identification of damage at par with constraint optimization related to the concept of GA, it is utter essential to broaden up the objective function. The suitable objective, which is required to be maximized by using the general rules of residual forces and taking into consideration several practical aspects, is given as follows:

$$
J_{o b j}\left(\beta_{1} \ldots \beta_{i} \ldots\right)=\frac{C_{1}}{\sum_{f=1}^{r} R_{f}^{*}\left(\beta_{1}^{*} \ldots \beta_{1}^{*} \ldots\right)^{T} R_{f}^{*}\left(\beta_{1}^{*} \ldots \beta_{1}^{*} \ldots\right)+C_{2}}
$$

where $C_{1}$ implies a constant used to control the value of the objective function $C_{2}$ represents a constant used to construct a well established function for the ideal case and $r$ represents the number of modes taken into consideration which is determined experimentally or used in simulated examples. In [56], the authors had used the approach of wave propagation having a synergistic combination with genetic algorithm in order to identify the damages in beam structures. In [57], the authors has proposed a technique of training a neural network taking into consideration the input parameters as strain and frequency whereas the output is taken to be the damage level. The neural network parameters are selected using GA. In [58], the authors had presented a GA-based methodology for the extraction of crack zone as well as aluminum made beam depth. The location of crack and depth in a cantilever beam is identified and constructed as an optimization problem. The optimal location and depth is found out by using binary and continuous genetic algorithms by implementing cost reduction scheme on the basis of extracted and computed changes in frequencies. Initially the chromosomes are arranged on the basis of their fitness. The selection probability $P_{n}$ for each chromosomes considering rank $\mathrm{n}$ is:

$$
\frac{N_{\text {keep }}-n+1}{\sum_{n-1}^{N_{k e e p}} n}
$$

Single point crossover is used for binary GA. In case of continuous genetic algorithm, the used variable value considered is unit offspring. $P_{\text {new }}$ is considered to be the outcome of binary associated variable illustrated as:

$$
P_{n e w}=\beta P_{m n}+(1-\beta) P_{d n}
$$

The interval $[0,1]$ is selected for $\beta$ and is termed to be a random value. Also, $P_{m n}$ is considered to be the $\mathrm{n}^{\text {th }}$ mother chromosome variable. Finally, $P_{d n}$ is nth variable associated with father chromosome. The methodology of genetic algorithm is implemented in this investigation for the identification of beam cracks. The identification methodology associated with the approach use unit and continuous GA for the identification of depth and crack. In [59], the researcher briefly defined a technique for damage identification of structure based on micro GA which utilizes test data involving noises and incompleteness. The computation of modal data is carried out by installing some sensors. In the primary phase, the expansion of mode shape data is executed in phase with all DOF related to the finite element model. The next step is to implement elemental energy quotient difference in order to investigate the damage location approximately. The final step includes the utilization of a micro-genetic algorithm for the quantification of the damage by minimizing the errors between the computed data and numerical outcomes. Ruotolo and Surface [60] used the methodology of genetic algorithms to identify structural damage in structure by the modal residuals optimization. In [61], the author had presented a combined methodology of genetic algorithm and finite element method for detecting and locating damage. In [62], the researchers had revealed a methodology based on nondestructive global damage detection and assessment computation associated with frequency changes and mode shapes of vibration of a structural system. This is an elementary level methodology based on finite-element model. 


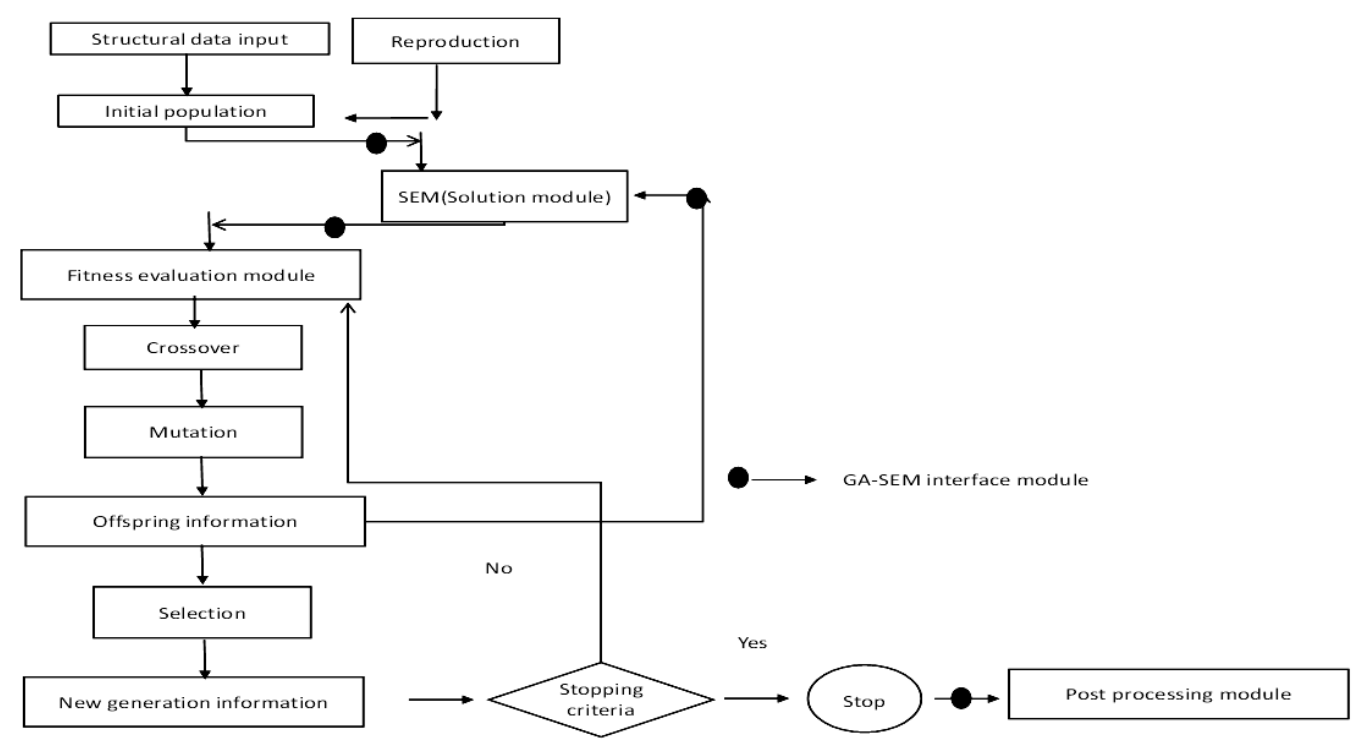

Figure 1: Flow chart of genetic search

Continuum damage mechanics suggest that the representation of damage should be done using a reduction factor of the element bending stiffness. In order to localize the area of damage in structures, an optimization approach with non-classical touch involving the implementation of genetic algorithm is laid down. Innumerable cases of damage instances has proved the efficiency of this method when applied to simulated beams and also by use of direct data from experiment which is extracted from the vibration tests of a beam. The proposed technique of genetic algorithm generates an appropriate location of damage and extreme detection while offering number of benefits in comparison to classical methods. In [63], the authors had presented an effective procedure involving optimization technique in order to locate multiple damage in structures. One indication that the structure is under the grip of damage is the natural frequency variation of the structure. The extraction of information on the basis of natural frequencies is accomplished by using a finite element analysis (FEA). A novel technique involving tweaked genetic algorithm(MGA) having novel operators termed as health as well simulation components are illustrated in significant way for detecting range and location of damages. The efficient combination of MGA and the ECBI that result in a effective robust tool for detecting structural damage is validated from the numerical results for different cases of damage with different sample. This methodology can be used to detect the real damage sites and extent thus decreasing the total number of FEA in comparison to the available tools like SGA-MDLAC. In [64], the authors had suggested a technique to compute the extent of damage as well as precise location using the concept of natural frequency shifts. The combination utilizes real genetic coded algorithm as an optimization tool to verify natural frequency with those extracted by using the technique of parametric finite element code via modified MDLAC index. A Binary-coded genetic algorithms (BCGA) concept was implemented for the detection of structural damage associated with GA technique [65]. In recent days, the trend of studies in the field of real-coded genetic algorithms (RCGA) is on the up rise [66, 67]. This approach works better with variables that are continuous and there is less requirement of storage than BCGA. An improvised GA technique for the detection of frame structure damages was presented by [68]. In their work they suggested discrete values to illustrate the damage. This methodology is composed of initial population of heuristic generation, two dynamically changing fitness functions on the basis of modal data and two appropriate mutation operators. In [69], the author suggested an algorithm in two stages in order to sense structural damage. The first step is to define an search algorithm in order to search for expected damages. In second case, the algorithm scanning is accomplished in order to uplift the level of knowledge. GA is utilized in all the cases. In [70], the authors had proposed a hybrid type real-coded genetic algorithm for the detection of structural damage. The objective function is incremented with a damage penalization in order to discard fake damage detection caused by experimental disturbance or error in computation. The algorithm verification is carried out using a three dimensional space frame structure taking onto consideration both single and multiple damage cases. This research reveals that the genetic algorithm approach used gives more accurate results than conventional optimization methods. The successful detection of real damage was made possible while neglecting the false damage detection. This methodology is widely used for large or complex damage criteria and preferred over traditional optimization techniques which fails to extract the global optimum. A hybrid methodology involving optic fiber sensor and GA was developed by [71] for structural health monitoring. The methodology involving random generation is utilized to develop the preliminary population having three individuals. The researchers have utilized the concept of objective function which is illustrated by addition of squared differences associated with the beam eigenvalues extracted obtained by a sensor termed as POF. Compilation of the frequency associated with the modal includes randomly generated individuals related to the initial population. The objective function is given as:

$$
f(m, d)=\sum_{i=1}^{i=3}\left(f_{\text {data }}^{i}-f_{\text {exp }}^{i}\right)^{2}
$$




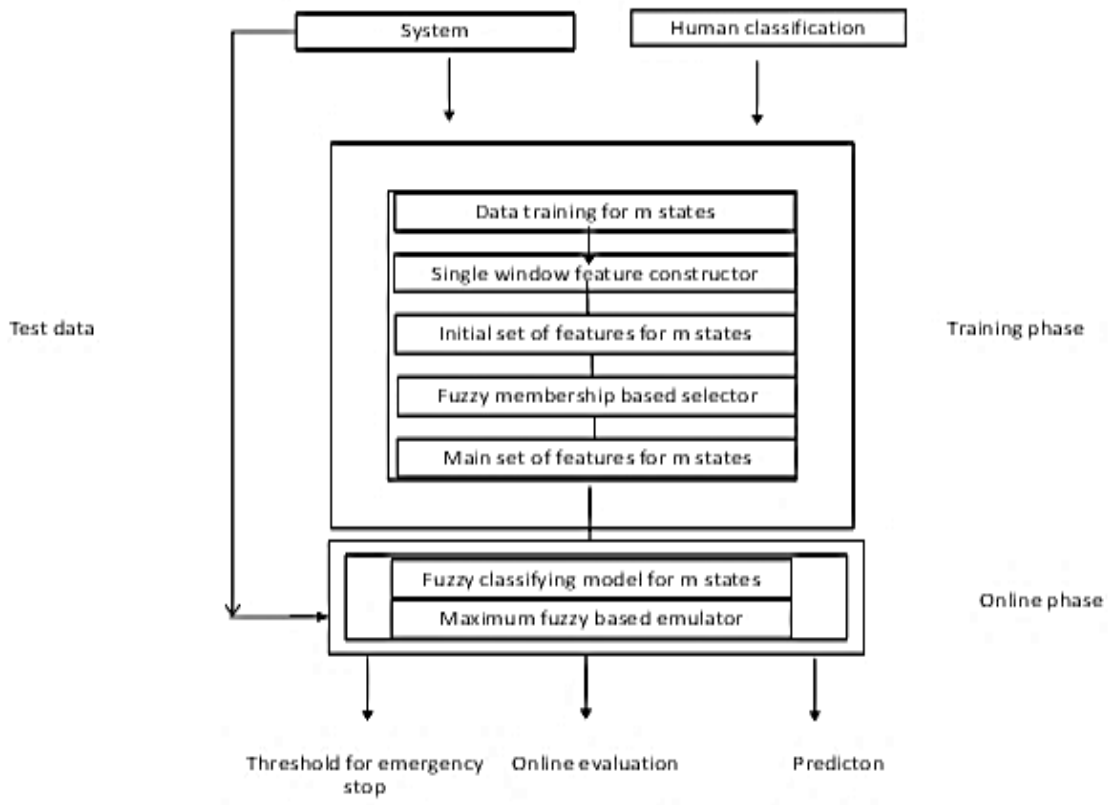

Figure 2: Fuzzy filter approach

objective function is carried out so that solution variables having minimal value will have the higher fitness value. GA is utilized in this investigation which is a novel approach. The one with the strongest feature is permitted to shift to the forthcoming generation. The approach of reimplementation associated with the chromosomes are embedded into the new population related to the forthcoming generation thus not permitting any variations in the GA. The approach of joint general GA along with sensor made of plastic optic fibre are depicted for the health monitoring of structures. The methodology utilized in this research can be implemented for identifying damages in structures made of concrete as well as composite materials. The identification of delamination in composite beams as well as joint structures utilizing an efficient identification concept was illustrated by [72]. The predicting technology based on modal analysis combined with damaged spectral element for extracting the structural response damage associated with the frequency domain is proposed. A novel type of curved genetic algorithm (GA) associated with a with finite element code for automatic is utilized for structural damage identification. The techniques involved in genetic search is illustrated in Figure 1. A technique for inverse problem is suggested for the detection and localization of damage in composite beam like structures by [73]. The developed methodology utilizes Genetic Algorithm (GA) as well as Particle Swarm Optimization (PSO) techniques. The basis of the objective function is the computation of natural frequencies and Modal Assurance Criterion. In [74], the author suggested a hybrid methodology based on of standard GA in order to improvise the stability associated with the EM algorithm involved in the findings of clusters optimizing number and also the parametric values thereby expanding the damage classified results. The importance of the illustrated approach is proved by utilizing real time sets of data extracted from the Z-24 Bridge situated in Switzerland. A varied feature GA was illustrated by [75] in order to detect the accurate locations as well as extents of the imparted minimal damages in the structure. The proposed methodology detects the damages to the suitable extent.

\subsection{Fuzzy logic}

In 1965, The concept of fuzzy theory was proposed by Zadeh [76]. Fuzzy algorithm is capable of processing simulated thoughts and judging capabilities of humans. One of the essential attributes of fuzzy control rule is its linguistic criteria which can be tweaked very easily and can be understood with ease. The nonlinear mapping can be handled effectively by the utilization of fuzzy set theory as well as fuzzy logic. The main attributes of fuzzy logic system is to deal uncertainty easily and with more flexibility thus making it popular among researchers. Fuzzy logic manages the oddly situations in a suitable way, also it is very sensitive to information such as it is possible for a peak may to get established as fault in the same time without creating problems [77]. Regarding the in-between laid dependencies, it is proved that the concept of fuzzy approaches results in superior outcomes $[78,79]$. One aspect that makes fuzzy system a convenient tool for analysis is that it has convincingly less number of rules when compared to classical expert system [80]. Fuzzy logic technique, has astonishing capabilities of damage detection in structures along with ambiguous data processing capabilities [81, 82]. In [83], the authors had shown an intelligent approach to alter the human procedure with a computer by characterizing a system based on fuzzy concept by utilizing decision approach based on human attributes. The feature of developed technology is that it will grant affordable way of encoding methodology related to the rules set. The designing of fuzzy expert system is laid down on the basis of FE model associated with simple beam. Also, it is successful in validating reliable source of damage detection for every scenario of damage analysis. There is $100 \%$ accuracy in the detection of damages by this system and no fake positives or negatives on the shapes of the mode obtained by impact testing and or by using vibrometer procedure that are non-contact. The analysis reveals 
that the expert system involving fuzzy portrayed in this paper displays a decisive and precise results in recognition of various cases of damage. The performance of thresholding based methods is overshadowed by the performance of this system mainly in the case of multiple damage. The elaborately defined example in this paper suggest that the thresholding based technique is capable of detecting only one of the two damaged areas but the expert fuzzy system proposed is well enough to detect both of the damaged areas. The decision process can be processed very easily by installing the damage detection system as an expert system. The intervention of fuzzy logic results in comfortable solution of the unreliability and denial within the rules set and while taking any decision. In [84], the authors had proposed a technique of conditioning monitoring and approach based on classification using fuzzy-filtering. There is a necessity of defining various models for differentiating different states of operation in a machine. This problem is discarded by model based on qualitative methods and signal based methods due to the involvement of innovative concept principle of modeling. In their work, the technique of qualitative model associated with fuzzy concept and statistic stated signal properties is combined synergistically. A conditioning monitoring system is designed on the basis of important signals, alternate measurements experimental data as well as the classifying knowledge of the system which is required to be verified. The concept behind the fuzzy filter is stated by a flow chart illustrated with Figure 2. The filtering methodology is illustrated relying on the concept of qualitative model based technique utilizing fuzzy concept in combination with statistics concept associated with signal based methods. The mentioned methodology gives the raw data conversion to a novel presentation for approaching the classification. In [85], the authors illustrated a technique for the validation of overlapping health fuzzy sets by utilizing presumed distributions of statistics associated with damage attributes. The superior impacts of implementing progressive stages of damages to be mention as crack, defect as well as flaw for laying down a systematic investigation of damage using the concept of supervised as well as unsupervised learning was mentioned by [86]. In [87], the authors implemented the methodology of fuzzy similarity for monitoring structural health utilizing damage pattern recognition. The health features are illustrated by fuzzy sets that are developed by utilizing the methodology of healthy observations. The representation of healthy as well as damaged states are accomplished by fuzzy membership functions which is utilized as a combination with piecewise linear functions. The model steel bridge is consider as a case study for identifying damage pattern in their work. The precise estimation of damage patterns is achieved by regularizing this methodology. The fuzzy set associate with health which is a left shouldered triangular membership function is illustrated as:

$$
\mu_{H}(\lambda)=\left\{\begin{array}{c}
1, \lambda \leq \bar{\lambda}_{H} \\
\frac{\left(\lambda H^{*}+\sigma_{H}\right)-\lambda}{\sigma_{H}}, \lambda H^{*} \leq \lambda \leq \lambda H^{*}+\sigma_{H} \\
0, \lambda \geq \lambda H^{*}+\sigma_{H}
\end{array}\right.
$$

$\left.\mu_{H}(\lambda)\right)$ is stated as membership linked to the fuzzy set illustrating a good forma with a mean of $\lambda H^{*}$ having a spread of $\sigma_{\lambda_{H}}$. The membership function with good health illustrate that healthy fuzzy set considers a data interval which are completely leaned towards healthy outcome. The technique of pattern recognition associated with damaged states with unknown capability sets is implemented utilizing the concept of fuzzy similarity as well as maximum convex degree. The methodology depicted in this investigation can precisely detect the damages in the structure. The proposed technique is nonspecific for any SHM system due to the fact that it is independent of the damage feature. An advanced methodology was illustrated by [88] for the identification of location as well as damages extremity in the area of stochastic structures relied on ARMA parametric model combined with fuzzy classification. The method suggested in this paper has a high significance as it uses fuzzy viewpoint on stochastic structural damage analysis. In this case, the feature vector is considered to be ARMA parameters. The ability of this technique is also minimize the stage at par with the optimization which is utilize to extract the values related to the membership functions of fuzzy technique by implanting changes of predicted ARMA values associated with membership functions. In this current investigation, the fuzzy classified inputs are ARMA model's parameters and the outputs are specified as elemental damaged numeric as well as the level of extremity. Considering all features, the antecedent fuzzy sets (membership function) is illustrated as:

$$
\alpha\left(\mathrm{f}_{\mathrm{i}}^{\mathrm{j}}\right)=\exp [0.5]\left(\frac{\mathrm{f}_{\mathrm{i}}^{\mathrm{j}}-\mathrm{m}_{\mathrm{i}}^{\mathrm{j}}}{\sigma_{\mathrm{i}}^{\mathrm{j}}}\right)^{2}
$$

where, $\alpha\left(f_{i}^{j}\right)=$ ith membership function of $\mathrm{jth}$ feature, $f_{i}^{j}=$ absolute value, $m_{i}^{j}=$ related mean value (midpoint) and $\sigma_{i}^{j}=$ variance of the jth feature in ith class. In [89], the authors suggested a noteworthy methodology on the basis of fuzzy clustering combined with computed frequency response function samples minimized via principal component projection in order to investigate damage detection in truss bridge model using vibration based technique. The preliminary data utilized in this investigation are the FRFs associated with the healthy as well as the damaged structure. The normalization of FRF data is carried out to eliminate the effects caused by the environmental and operational variability. The analysis by principal component at par with kernel principal component investigation technique are laid down for handling the compression of data. In extraction methodology of damage features, the principal components of median values are used. Finally, fuzzy c-means(FCM) clustering algorithm is applied for the categorization of structural damage detection features. In [90], the authors had suggested an approach of novel binary phase detection of damages in structures utilizing the theory of fuzzyneuro methodology and techniques of data fusion. This method is widely used for the identification of damage considering the condition that computed sample is vast and involves uncertainties. Primal phase of damage detection involves the collection of modal attributes of structure from the structural vibration responses that are embedded as an input to the FNN. The output values associated with the FNN are defuzzified for delivering a rough evaluation damages in structure. In the second phase, FNN model reveals three output values which are inputted to the center of data fusion in order to execute fusion computation. The result is then filtered using threshold function in order to carry out final fusion decision. Thus a superior quality damage assessment methodology is achieved. The innovative approach is implemented in 7 DOF building for the validation of damage identification of structure. 
The results are effective, reliable and satisfactory. In [91], the researchers had proposed an modernized approach to detect damage in structures using a new algorithm based on the fuzzy cognitive map (FCM). In this research, damage in structures is modeled with the help of continuum mechanics approach. The technique of modeling using finite element method for cantilevers is utilized in order to compute the variation of first six beam frequencies due to structural damage. In [92], the researchers illustrated the concept of structural damage detection based on data fusion as well as semi-supervised fuzzy C-means clustering. This method performs superiorly when compared with other methods for detecting damages in structures. The experimental results associated with a benchmark model validates the effectiveness of the proposed methodology. In [93], the authors illustrated a fuzzy inference model for the extraction of building damage hazard, normally associated with the non-technical building houses considering special sort of earthquake event. The laid down model consists of 3 level model consisting of fuzzy rules which utilizes numerable data associated to the damaged buildings obtained from the impingement of earthquake occurred in 2013 at Indonesia. The important contribution associated with this research is vested towards the development of the function as well as membership related to fuzzy taking into consideration the variable of each determinant associated to building house damage warning as well as three levels of fuzzy inference procedure for extracting building house damage hazard as an earthquake occurrence. A system based on decision making and associated with an adaptive network-based fuzzy inference system (ANFIS) model was proposed for the extraction of damage level of building by [94]. The suggested methodology was tested over earthquake data set of Bam city in Iran. The proposed methodology was accurate up to $76.36 \%$ for the detection of damage degree of building. A technique for damage identification in buildings using the approach of superior dimension remote-sensing imaging combined with fuzzy reasoning concept was presented by [95].

\subsection{Concept of Neural Network}

A neural network consists of inter connected neurons and layers and it is one of the most important means of computing weights which are relied on the connections illustrated as learning algorithms. In [96], the authors has vividly described the concept of common anatomy of neural network by sub dividing it into seven important zone as follows: i) processing unit set, ii) activation set of processing unit, iii) calculation of processing unit output using a function, iv) connectivity pattern alongside the processing unit, v) implementation of propagation rule, vi) instillation of activation function and vii) confirmation of learning rule. In [97], the author had investigated the primary research stage inclined at the development of automatic monitoring methods for the detection of damage in structure. In their study, the technique of self-organization and learning capabilities of neural network are explored for the assessment of structural damage. The concept involved is the training approach of neural network to identify the undamaged structure behavior alongside the behavior of the structure considering numerous possibility of damage states. The detection of any existing damage can be made possible by impinging the training network for the computation of responses from structure. This concept was implemented to a simple structure to get a motivated results. The initial outcome of results verifies that the neural network are capable enough to learn the nature of damaged and undamaged structures and thus can be used to identify the damaged member and the extent of the damage by the approach of patterns in the frequency response of the structure. In [98], the author utilized the concept of counter propagation neural network for revealing the beam damages, also damages in a frame as well as support movements of a beam along axial direction. The research involves a wide range of diagnostic parameters, along with static displacements, natural frequencies, mode shapes and other mode shapes parameters. The fetching results are quite interesting showing that these parameters can be utilized as a diagnostic parameters for artificial neural network applied to structural engineering. In [99], the researchers developed an artificial neural network technique associated with system identification concepts extracting the characteristics of composite structures damage. The methodology implemented in this research consider a training phase as well as recognition phase. The different types of damage considered to be as patterns are associated with structures candidate model in the training phase. The area and the extremeness of the damage decides the arrangements of patterns into pattern classes. In order to extract the transfer functions, the identification of system are carried out which is an important attributes associated with the structural systems. The extracted transfer functions is used as input patterns for training which are transferred to multi-layer perceptron. Numerical validation proves the efficiency of the developed technique. In [100], the authors implemented an architecture on the basis of multiple layer perceptron in combination with the learning algorithm based on backpropagation for modeling a bridge by utilizing data from damaged states. By using the methodology of general structure analyzer, the patterns of the training were laid down by predicting the zones of structural damages. By creating a comparison between output and the performance data that are created algorithmically without considering it in the training process, the working of the network was displayed. The problems associated to the working of the network is thoroughly investigated. For the estimation of structural damage it can be accomplished from various investigation done that the perceptron model is completely applicable. For the described case, the functioning of the architecture of an individual layer is not more sophisticated than the performance with double hidden layers. The investigation done on the calculated data based on the implications of engineering is considered by the evidence that for the identification recognition task barely a certain area in the structure required to prepare the network. In [101], the authors conducted an experiment five storey frame shake table and validated that there are problems leading to damage states occurred during the event of implementation of neural concept that is trained utilizing trained samples obtained by using FEM. The obtained results proves the superiority of the technique. In [102], the authors illustrated a novel network associated with proposition for the identification of damages in structure. In the preliminary part, the technique initiates with identification of system utilizing networks on the basis of neural concept recognition in order to extract the damaged as well as undamaged states. The next phase deals with the structural damage identification using neural concept in combination with damage identification network for the area detection as well as severity of the structural damage. Considering $\mathrm{n}$ hidden layer in the network having output with $\mathrm{k}^{\text {th }}$ node: 
Step 1: Training of decentralized neural networks

Structure(Undamaged)

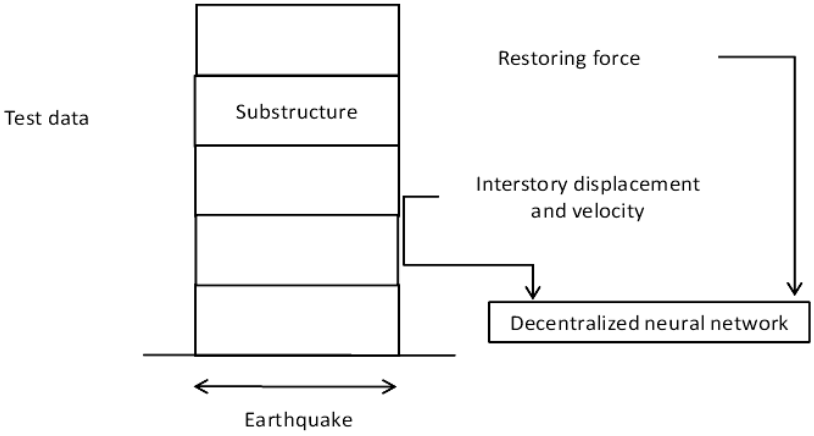

Step 2: Decentralized damage detection

Structure(Damaged)

Figure 3: Decentralized damaged detection

$\mathrm{H}_{\mathrm{nj}}$ is the illustrated output at par with $\mathrm{j}^{\text {th }}$ node having $\mathrm{n}^{\text {th }}$ hidden layer. Again, $\theta_{\mathrm{ok}}$ is the threshold parameter related to $\mathrm{k}^{\text {th }}$ node of the output. Also, $W_{\text {hnj,ok }}$ is termed to be the weight of the $j^{\text {th }}$ node embedded in $n^{\text {th }}$ hidden layer of the $\mathrm{k}^{\text {th }}$ node of the output. The activation function is illustrated by $\mathrm{f}$. The approaches implemented in this research is highly effective in structures involving nonlinearities, as neural concept can handle linearity and nonlinearity with same technique. An innovative methodology of decentralized information structures related to the neural network concept was proposed by [103]. An identification technique involving parametric damage with decentralized pathway is implemented to the structures with multi degrees of freedom. In preliminary stage, detection of damages associated with substructures of a multi degree of freedom system is implemented and is applied by the method of neural networks. The training of the decentralized neural network required for the detection of analogous substructure is carried out based on displacements as well as velocity computations obtained from a good health substructure system as well as from the substructure restoring force. The differences in forces between the damaged substructures as well as the undamaged substructures is computed by means of trained decentralized identification neural concept. The figure 3 demonstrates the block diagram related to decentralized damage detection with the application of neural networks. The significance quality level of this methodology was inspected using numerical simulations. In this current research, the investigator has shown the effectivity of this method by demonstrating it as a practical tool for damage detection which can be utilized to structure-unknown smart civil structures. In [104], the authors laid down the technique of modular neural network approach in for the extraction of crack zone as well as depth associated with a cantilever beam. In the mentioned investigation, principal component analysis network is implemented for size mitigation as well as for unearth the concealed structure associated with the data set. In the adopted modular network approach, the crack location is estimated using one neural network whereas the other is used for computing depth of crack. In [105], the researchers presented an algorithm for the detection of damage in beam like structures with prediction of damaged ranges and zone by implementing the novel methodology of global and local vibration dependent analysis samples as input in neural concepts. Performance sensitivity analysis give rise to the essential features for damage detection. Various input-output sets are incorporated to various ANNs. The verification of input robust features used in the methodology as well as the actuation of the experimental uncertainties are done by generating artificial random noise and adding noise free data during the training procedure of the ANNs. The procedure of sensitivity analysis is carried out on the extracted features by using different modes of vibration taking into account the effect of the area of damage as well as severity before introducing them to ANNs. The various steps involved in the investigation starting from vibration based analysis for feature extraction in order to use as an input for the ANNs, noise level on these features, the methodology of the experiments, measuring instruments to the effectiveness verification at different vibration modes plays a significant role in extremity and location forecasting of the damage in beam like structures. In [106], the authors had proposed a methodology for damage detection using neural networks in association with modal data which impart the parameters of input to the modeling errors. In their study, to implement the methodology practically, the estimation of damage in bridge structures is demonstrated utilizing the technique of ambient vibration samples generated by traffic loadings. By initiating two numerical processes, the effectivity of the laid down concept is validated. The next step involves tests in laboratory as well as field tests on the structure of the bridge. The results are promising and effective which validates the efficiency of the neural network technique for damage identification, locations detection and severity analysis. In [107], the researchers illustrated a MLP neural network relied concept for damage estimation of structure related to the truss bridge joints, which is obtained from modal specification of the structure. Two mathematical investigation samples are illustrated to confirm the superiority of neural network concept. In [108], the authors presented an innovative approach of neural network based structural damage detection. The proposed methodology can be subdivided into categories. The first step includes system identification techniques that uses neural system identification networks (NSINs) to track the undamaged and damaged states of a structural system. The second step is associated to structural damage detection that uses trained NSINs to create free vibration responses taking into 
consideration the same initial condition or impulsive force. The level of changes can be made available by comparing the periods and amplitudes of the free vibration responses of the damaged and undamaged states. In [109], the authors demonstrated a statistics based neural network approach by considering finite element modelling error as well as measurement noise for the detection of structural damages. The investigation on numerical as well as experimental outcomes reveals that the superiority of statistical neural network concepts approach in comparison to the normal neural network approach generates more precise identification of damages in structure. Once the model training of neural network is over, the testing samples are then used to identify the locations and severities of any damages. In [110], the authors investigated a damage detection procedure with the help of identification of pattern methodology associated with vibration. The strategy is evaluated utilizing a FEM of a suspension bridge which is a century old. The response spectra give rise to feature vectors which was installed to binary unsupervised neural networks for evaluation. Investigation reveals that the tweaking of the sensitivity of the neural networks is accomplished for achieving a superior rate of damage detection along with the existence of noisy signals. In [111], the authors suggested the methodology of novelty detection and damage computation. In this process, signal parameters obtained from reference structure are used as a data set. Also soft computing methods are used to notify about the damage visualization, location and its type. The results obtained from the investigation shows that the suggested methodology makes automation of structure testing possible and can be applied to SHM systems. In this investigation, a two-stage SHM algorithm was developed which can predict structure damaged height and width. Neural Network (NN) trained novelty detection is used for the first level identification. The second level of identification is conducted using the NN trained for damage prediction. In [112], the authors proposed a damage detection methodology on the basis of computational method to identify damage in structures using neural networks. In this process, the training of the neural network is done for the recognition of the pattern of static value associated with the undamaged structure as well as of the structure having several possible damage extent and location which were modeled as random states. The damages in the cantilever beam was identified using this methodology. This study reveals the fact that the proposed methods using strain is more effective than the displacement method. In [113], the researchers presented an approach for the detection of small damage in structures using ANN technique with progressive substructure zooming. In this work, a combination of substructure technique along with a multistage ANN models in order to detect the area and extremity of damage. The input for ANN are considered to be modal parameters such as frequencies and mode shapes. The higher performance of the technique is validated using a two-span continuous concrete slab structure and a three-story portal frame. The experimental results shows that this approach is able to identify all the simulated damages in the structure. An identification methodology for the extraction of damages in structure by implementing the technique of parametric identification combined with iterative neural network (NN) concept was proposed by [114]. A variable backpropagation learning algorithm is proposed for tackling possible saturation of the sigmoid function as well as to run the training process. The structural parameters are predicted by utilizing the trained NN model which is implemented in measured dynamic attributes. The extracted structural parameters is then impinged in the finite element model for computing the dynamic characteristics. The obtained structural parameters is utilized for the identification of the location as well for examine how severe is the structural damage. In [115], the authors illustrated a particle swarm optimization-based methodology in order to train the NN (NN-PSO). The suggested approach is well capable of handling the problem of predicting failures in structure associated with multistoried reinforced concrete buildings. The superiority of the methodology is validated with the help of experimental results. In [116], the researchers developed a damage detection technique that uses 3 alternate neural networks. In order to analyze the model, a tiny dataset having ground-level image data of damaged buildings was extracted. Experimental results demonstrated the efficiency of the proposed method. In [117], the authors proposed a novel approach for the detection of structural damage as well as estimation utilizing incomplete noisy modal data and artificial neural network (ANN). A feed-forward back propagation network is suggested for the estimation of the structural damage location and severity. In [118], the author illustrated an innovative, fast and precise identification of damages in structure using 1D Convolutional Neural Network. The illustrated technique performs vibration based damage identification as well as localization of the damage in real-time and generates superior outcomes.

\subsection{Hybrid Techniques}

Fuzzy logic, artificial neural network and genetic algorithm are the three main important categories of intelligent techniques that tries to implement the perception of human intelligence using different methodologies. There is positive and negative attributes of each methodology that differentiates among each other. The positivity of neural network is that it can learn accurately from data and establish highly nonlinear mapping among various platforms but it is concealed to the users and it has very low reasoning capabilities. This drawbacks can be compensated by the techniques of IFTHEN rules and logical inference from the concept of fuzzy logic. The linguistic models is the main approach of fuzzy logic that uses the same decisions making capabilities of human beings as in real life. Linguistic models inherits high reasoning and nonlinear mapping capabilities. But the constraint embedded to fuzzy systems is that it cannot cope up with the ability of learning and cannot shape up according to a new ambient. The information processing systems like classifiers and controllers are the main objectives of artificial neural network and fuzzy logic unlike genetic algorithm. The genetic algorithm has a higher degree of parallel searching capabilities that enables it to search multi-peak spaces. Another attributes of genetic algorithm is that it is not dependent on continuity of the parameter space. Apart from the positivity of genetic algorithm, the drawback of genetic algorithm is that it cannot be used alone as modeling techniques. It is very much efficient when it is made to work in parallel with other modeling techniques. The combination of all three intelligent concepts will yield maximum favorable outcome and vastly accepted as a hybrid methodologies [119]. A learning technique at par with the neural network is developed by [120] which is relied on the genetic fuzzy combination. The approach is to facilitate training to the radial basis function associated with the neural network. The unique approach is a blend of genetic algorithm with 
fuzzy logic in order to tweak the centers as well as widths linked to the RBFNN. By utilizing the technique of linear least square method, the optimization of neural network connection weights is achieved. The output linked to the RBF fuzzy neural network is stated as:

$$
\mathrm{Y}_{\mathrm{pi}}=\sum_{\mathrm{k}=1}^{3^{6}} \mathrm{~W}_{\mathrm{ik}} \bar{\alpha}_{\mathrm{pk}}, i=1,2
$$

The matrix $\alpha$ depicts the firing strength of all rules. Also, $\mathrm{W}$ is illustrated as the output linked weight matrix. Again, Y is considered to be output matrix. The equation depicting the fitness function with genetic algorithm is:

$$
F_{i=\{}\left\{\begin{array}{c}
\bar{J}+2 \sigma-J_{i}, \text { if } J_{i}<\bar{J}+2 \sigma, i=1,2, \ldots 200 \\
0, \text { otherwise }
\end{array}\right.
$$

The mean value associate linked to the objective function is defined by J. Also, $\sigma$ is considered to be standard deviation and $\mathrm{J}_{\mathrm{i}}$ is the parameter associated with objective function. A hybrid neuro-genetic algorithm for evaluating the damages in the structure is presented by [57]. Current investigation reveals that two hidden layer network was chose taking into consideration back propagation algorithm with momentum coefficients as training algorithm. The network parameters in this case which are number of neurons associated to hidden layer, learning as well as momentum coefficients are taken as variables. Also, genetic algorithm is implemented for choosing the appropriate sets of the parameter. Superiority of the developed algorithm is proved by implementing dual structures consisting of a frame and a beam. The equation representing the objective function linked to the optimization problem is:

$$
\mathrm{E}\left(\mathrm{X}_{\mathrm{k}, \mathrm{W}}\right)=\frac{1}{\mathrm{P}} \sum_{\mathrm{k}=1}^{\mathrm{p}} \sum_{\mathrm{m}=1}^{\mathrm{N}_{\mathrm{n}}}\left(\mathrm{y}_{\mathrm{k}, \mathrm{m}}-\mathrm{o}_{\mathrm{k}, \mathrm{m}}\right)^{2}
$$

the desired and obtained outputs for the $m^{\text {th }}$ output and $k^{t h}$ training instance are $y_{k, m}$ and $o_{k, m}$ respectively. In [121], the authors presented a damage detection algorithm on the basis of neuro fuzzy hybrid system for the study of location as well as severity predictions of cracks associated to beam-like structures. In [122], the authors proposed an appropriate fuzzy inference system (FIS) which is also termed as an Adaptive Neuro-Fuzzy Inference System for the detection of damage level in roads. The extracted results display the effectiveness and preciseness of the NeuroFuzzy systems for road damage detection. In [123], the authors developed a semi-automated Mamdani based fuzzy decisionmaking system for the identification of damages in buildings by the utilization of textural features. For the improvisation of the level of automation in Mamdani fuzzy system, a genetic algorithm was utilized to find its optimized parameters associated with membership functions.

\section{Conclusions}

Structural health monitoring is a wide are of research and has different intentions depending on the various scenario. But approaches that need to be implemented have common and specific component classes at the levels mentioned as follows: a) Need for sensors, b) storage of data, c) data transmission technique, d) database management system in order to carry out feature extraction, e) development of model from the extracted data, f) past data analysis for knowledge and g) steps related to decision making on the basis of features that is identified in combination of known models. The design state of structural health monitoring is an important phase where consideration needs to be implemented in order to monitor the substructures related to uncertain or critical performance [124]. This critical survey revealed various positive attributes and capabilities of intelligent technique in the detection damaged structures associated to civil engineering. The genetic algorithm can generate good approximate solutions related to complex optimization problems. Fuzzy logic displayed its capabilities on handling the structural systems associated with complexities. The fuzzy methodology can handle uncertainty with ease. The neural network established its identity as it has above well capabilities in detecting cracks in structures. It also shows superior performance in detecting damage index of cases associated to the free decay of structures. It is to be noted down that hybrid techniques are more effective than other conventional artificial intelligent methods in structures as it induces the quality of individual intelligent techniques in a single methodology. The intelligent technique is considered to be the most popular tools for damage identification due to its precise, reliable and low-cost solution nature. The main intention of this survey paper is to provide an in-depth knowledge to the researcher about the application of various intelligent approaches in the area structural health monitoring. This research will impart a vast knowledge of intelligent tools among the researchers who wants to conduct analysis and monitoring of structures under various conditions. This survey paper will generate a brief idea among the researchers, the several ways of initiating research in the area of structural health monitoring.

\section{References}

[1] Richardson, M.H. Detection of damage in structure from changes in their dynamic (modal) properties---a survey. 1980; NUREG/CR1431, Washington, DC: US Nuclear Regulatory Commission.

[2] Rytter, A. Vibration based inspection of civil engineering structures. $\mathrm{PhD}$ Dissertation. 1993; Department of Building Technology and Structural Engineering, Aalborg University, Denmark.

[3] Chang, P.C.;Flatau, A.; Liu, S.C. Review paper: health monitoring of civil infrastructure. Struct Health Monit, 2003; Volume 2, Issue No. 3, pp.257--67.

[4] Doebling, S.W.; Farrar, C.R.; Prime, M.B.; Shevitz, D.W. Damage identification and health monitoring of structural and mechanical systems from changes in their vibration characteristics: a literature review. 1996; Report LA-13070-MS, Los AlamosNationalLaboratory, Los Alamos, NM.

[5] Ubertini, F., Comanducci, G., Cavalagli, N., Vibration-based structural health monitoring of a historic bell-tower using output-only measurements and multivariate statistical analysis. 2016; Volume 15, Issue No.4, pp.438-457.

[6] Bhuiyan, M. Z. A., Wang, G., Wu, J., Cao, J., Liu, X., Wang, T., Dependable Structural Health Monitoring Using Wireless Sensor Networks, 2017; IEEE Transactions on Dependable and Secure Computing, Volume 14, Issue No. 4, pp. 363-376.

[7] Carden,E.P.;Fanning,P.Vibration based condition monitoring: A review, Structural Health Monitoring,2004; Volume 3, Issue No. 4, pp.355--377.

[8] Auweraer, H.V. International research projects on structural damage detection, Damage Assessment of Structures Key Engineering Materials, 2001; Volume 204, Issue No. 2, pp.97-112.

[9] Shi, Z.Y.:Law, S.S.; Zhang, L.M. Structural damage detection from modal strain energy change, Journal of Engineering Mechanics-ASCE , 2000; Volume 126, Issue No.12,pp.1216--1223.

[10] Gawronski, W.; Sawicki, J.T. Structural damage detection using modal norms, Journal of Sound and Vibration, 2000; Volume 220, Issue No. 1, pp.194-198.

[11] Rytter, A. Vibration based inspection of civil engineering structures, $\mathrm{PhD}$ Dissertation.Department of Building Technology and Structural Engineering, Aalborg University, Denmark; 1993.

[12] Tsou, P.; Shen, M.H.H. Structural damage detection and identification using neural networks, AIAA J, 1994; Volume 32, pp. 176-183.

[13] Mares, C.; Surace, C. An application of genetic algorithms to identify damage in elastic structures, J Sound Vib,1996; Volume 195, pp. 195-215. 
[14] Fuat, E.; Oguzhan, H.; Ilker, T.; Hakan, K.Optimal design of planar and space structures with genetic algorithms, Compos.Struct., 2000; Volume 75, pp. 209-224.

[15] Koh, C.; Chen, Y.; Liaw, C. A hybrid computational strategy for identification of structural parameters, Computers and Structures, 2003; Volume 81, Issue No. 2, pp. 107-117.

[16] Friswell, M. I.; Penny, J. E. T.; Garvey, S. D. A combined genetic and eigensensitivity algorithm for the location of damage in structures, Compos.Struct., 1998; Volume 69, pp.547-556.

[17] Chou, J.; Ghaboussi, J. Genetic algorithm in structural damage detection, Compos. Struct., 2001; Volume 79, pp. 1335-1353.

[18] Chen, D.; Wang, W. J.Classification of wavelet map patterns using multilayer neural networks for gear fault detection, Mechanical Systems and Signal Processing, 2002; Volume 16, Issue No. 4, pp. 695-704.

[19] Garg, A. K.; Roy Mahapatra, D.; Suresh, S.; Gopalakrishnan, S.; Omkar, S. N.Estimation of composite damage model parameters using spectral finite element and neural network, Composites Science and Technology, Volume 64, Issue No. 16, pp. 2477-2493.

[20] Ko, J. M.; Sun, Z. G.; Ni, Y. Q. Multi-stage identification scheme for detecting damage in cable-stayed KapShuiMun Bridge, Engineering Structures, 2002; Volume 24, Issue No. 7, pp.857-868.

[21] Gao, J.Introduction to intelligent information processing. Beijing: China Machine Press, 2004.

[22] Pedrycz, W.Computational intelligence. Boca Raton, FL: CRC Press, 1997.

[23] Ganguli, R.A fuzzy logic system for ground based structural health monitoring of a helicopter rotor using modal data, Journal of Intelligent Material Systems and Structures, Volume 12, Issue No. 6, pp. 397-407.

[24] Silva, S.D.; Dias, M.; Lopes, V.; Brennan, M.J.Structural damage detection by fuzzy clustering, Mechanical Systems and Signal Processing, 2008; Volume 22, Issue No. 7, pp. 1636-1649.

[25] Kong, F.; Chen, R. A combined method for triplex pump fault diagnosis based on wavelet transform, fuzzy logic and neuro-networks, Mechanical Systems and Signal Processing, 2004; Volume 18, Issue No. 1, pp. 161-168.

[26] Meyyappan, L.; Jose, M.;Dagli, C.; Silva, P.; Pottinger,H. Fuzzy-neuro system for bridge health monitoring, 22ndInternational Conference of the North American Fuzzy Information Processing Society, NAFIPS 2003, Chicago, IL, 2003; pp. 8-13.

[27] Roy, N.; Ganguli, R. Filter design using radial basis function neural network and genetic algorithm for improved operational health monitoring, Applied Soft Computing, 2006; Volume 6, pp. 154-169.

[28] Lee, Y.S.; Chung, M.J.A study on crack detection using Eigen frequency test data, Computers \&Structures, 2000; Volume 77, Issue No. 3, pp.327-342.

[29] Kim, J.T.; Ryu, Y.S.; Stubbs, N. Damage identification in beam-type structures: frequency-based method vs. mode-shape based method, Engineering Structures,2003; Volume 25, Issue No. 1, pp. 57-67.

[30] Deraemaeker, A.; Reynders, E,; De Roeck, G.; Kullaa, J.Vibration-based structural health monitoring using output-only measurements under changing environment, Mechanical Systems and Signal Processing, 2008; Volume 22, Issue 1, pp. 34-56.

[31] Khoo, L.M.; Mantena, P.R.; Jadhav, P. Structural damage assessment using vibration modal analysis, Structural Health Monitoring, 2004; Volume 3, Issue No. 2, pp. 177-194.

[32] Yan, A.M.; Kerschen, G.; De Boe, P.;Golinval, J.C. Structural damage diagnosis under varying environmental conditions---Part I: A linear analysis, Mechanical Systems and Signal Processing, 2005; Volume 19, pp. 847-864.

[33] Gelman, L.The new frequency response functions for structural health monitoring, Engineering Structures, 2010; Volume 32, Issue No. 12, pp. 3994-3999.

[34] Bandara, R. P.; Chan, T. H. T.; Thambiratnam, D.P. Structural damage detection method using frequency response functions, Structural Health Monitoring, 2014; Volume 13, Issue No. 4, pp. 418-429.

[35] Curadelli, R.O.; Riera, J.D.; Ambrosini, D.; Amani, M.G. Damage detection by means of structural damping identification, Engineering Structures, 2008; Volume 30, Issue No. 12, pp. 3497-3504.

[36] Jaishi, B.; Ren, W-X. Damage detection by finite element model updating using modal flexibility residual, Journal of Sound and Vibration, 2006; Volume 290, Issues No. 1-2, pp. 369-387.

[37] Huth, O.; Feltrin, G.; Maeck, J.; Kilic, N.; Motavalli, M. Damage Identification Using Modal Data: Experiences on a Prestressed Concrete Bridge, Journal of Structural Engineering, 2005; Volume 131, Issue No. 12, pp.1898-1910.

[38] Xia, Y.; Hao, H.; Brownjohn, J. M. W.; Xia, P.-Q. Damage identification of structures with uncertain frequency and mode shape data. Earthquake Engng. Struct. Dyn., 2002; Volume 31, pp.1053-1066.

[39] Furukawa, A.; Otsuka, H.; Kiyono, J. Structural Damage Detection Method Using Uncertain Frequency Response Functions, Computer-Aided Civil and Infrastructure Engineering, 2006; Volume 21, pp.292-305.
[40] Yan, J.; Cheng, L.; Wu, Z.Y.; Yam, L.H. Development in vibration-based structural damage detection technique, Mechanical Systems and Signal Processing, 2007; Volume 21, Issue No. 5, pp. 2198-2211.

[41] Hou, Z.; Noori, M.; Amand R. St.Wavelet-Based Approach for Structural Damage Detection, Journal of Engineering Mechanics, 2000; Volume 126, Issue No. 7, pp. 677-683.

[42] Escamilla-Ambrosio, P.J.; Liu, X.; Lieven, N.A.J.; Ramírez-Cortés, J.M. Wavelet-fuzzy logic approach to structural health monitoring, Fuzzy Information Processing Society (NAFIPS), 2011; Annual Meeting of the North American, El Paso, Texas, USA

[43] Lynch, J. P.; Loh, K. J. A Summary Review of Wireless Sensors and Sensor Networks for Structural Health Monitoring, The Shock and Vibration Digest, 2006; Volume 38, Issue No. 2, pp. 91-128.

[44] Cho, S.; Yun, C-B.; Lynch, J. P.; Zimmerman, A. T.; Spencer Jr., B. F.; Nagayama, T. Smart Wireless Sensor Technology for Structural Health Monitoring of Civil Structures, Steel Structures, 2008; Volume 8, pp. $267-$ 275.

[45] Aoki, S.; Fujino, Y.; Abe, M. Intelligent Bridge Maintenance System Using MEMS and Network Technology, In Smart Systems and NDE for Civil Infrastructures, San Diego, CA, Proceedings of the SPIE, 2003; Volume 5057, pp. $37-42$.

[46] Casciati, F.; Faravelli, L.; Borghetti, F.; Fornasari, A. Tuning the Frequency Band of a Wireless Sensor Network, In Proceedings of the 4th International Workshop on Structural Health Monitoring, Stanford, 2003; pp.1185-1192.

[47] Ou, J.; Li, H.; Yu. Development and Performance of Wireless Sensor Network for Structural Health Monitoring," Smart Structures and Materials, , Proceedings of the SPIE, 2004; Volume 5391, pp.765-773.

[48] Wang, Y.; Lynch, J. P.; Law, K. H. Wireless Structural Sensors Using Reliable Communication Protocols for Data Acquisition and Interrogation, Proceedings of the 23rd International Modal Analysis Conference, 2005.

[49] Camp, C.; Pezeshk, S.; Cao, G. Optimized Design of Two-Dimensional Structures Using a Genetic Algorithm, Journal of Structural Engineering, 1998; Volume 124, Issue No. 5, pp. 551-559.

[50] Jenkins, W. M. Towards structural optimization via the genetic algorithm, Computers \& Structures, 1991; Volume 40, Issue No. 5, pp. 1321-1327.

[51] Rajeev, S.; Krishnamoorthy, C. S. Discrete optimization on structures using genetic algorithms, J. Struct. Eng., 1992; Volume 118, Issue No. 5, pp. 12331250.

[52] Larson, C. B.; Zimmerman, D. C. Structural model refinement using a genetic algorithm approach, Proc., 11th Int. Modal Analysis Conf., Society for Experimental Mechanics, Kissimmee, Fla., 1993; pp. 1095-1101.

[53] Yong, X.; Hong, H. A Genetic Algorithm for Structural Damage Detection Based on Vibration Data. School of Civil and Structural Engineering, Nanyang Technological University.

[54] Rao, M. A.; Srinivas, J.; Murthy, B. S. N. Damage detection in vibrating bodies using genetic algorithms, Computers and Structures, 2004; Volume 82, pp. 963-968.

[55] Tso W.K.; Zhu, T. J. Design of torsionally unbalanced structural systems based on code provisions I: ductility demands, Earthquake Engineering \& Structural Dynamics, 1992; Volume 21, Issue No. 7, pp. 609-627.

[56] Krawczuk, M. Application of spectral beam finite element with a crack iterative search technique for damage detection, Finite Element Anal. Des., 2002; Volume 38, pp. 537-548.

[57] Sahoo, B.; Maity, D. Damage assessment of structures using hybrid neurogenetic algorithm, Appl. Soft Comput., 2007; Volume 7, pp. 89-104.

[58] Vakil-Bagmisheh, M-T.; Peimani, M.; Sadeghi, H.; Ettefagh, M. M. Crack detection in beam-like structures using genetic algorithms, Applied Soft Computing, 2008; Volume 8, pp. 1150-1160.

[59] Au, F. T. K.; Cheng, Y. S.; Tham, L. G.; Bai, Z. Z. Structural damage detection based on a micro-genetic algorithm using incomplete and noisy modal test data, , Journal of Sound and Vibration, Volume 259, Issue No. 5, pp. 1081-1094.

[60] Ruotolo R.; Surace C.Damage assessment of multiple cracked beams: numerical results and experimental validation, Journal of Sound and Vibration, 1997; Volume 206, Issue No. 4, pp. 567-588.

[61] Khatir, S.; Belaidi, I.; Serra, R.; Benaissa, B.; Saada, A. A.Genetic Algorithm Based Objective Functions Comparative Study for Damage Detection and Localization in Beam Structures, Journal of Physics: Conference Series, 2015; Volume 628.

[62] Perera, R.; Torres, R. Structural Damage Detection via Modal Data with Genetic Algorithms, Journal of Structural Engineering, 2006; Volume 132, Issue No. 9, pp. 1491-1501.

[63] Nobahari, M.; Seyedpoor, S.M. Structural damage detection using an efficient correlation-based index and a modified genetic algorithm, Mathematical and Computer Modelling, 2011; Volume 53, pp. 1798-1809.

[64] Gomes, H.M.; Silva, N.R.S.Some comparisons for damage detection on structures using genetic algorithms and modal sensitivity method, 2008; Volume 32, pp. 2216-2232. 
[65] 65. Perera, R.; Manzano, C. Performance assessment of multicriteria damage identification genetic algorithms, Computers \& Structures, 2009; Volume 87, Issue No. 1-2, pp. 120-127.

[66] 66. Hao, H.; Asce, M.; Xia, Y.Vibration-based damage detection of structures by genetic algorithm, Journal of Computing in Civil Engineering, 2002; Volume 16, Issue No. 3, pp. 222-229.

[67] He,R-S.; Hwang, S-F. Damage detection by an adaptive real-parameter simulated annealing genetic algorithm, Computers and Structures, 2006; Volume 84, Issue No. 31-32, pp. 2231-2243.

[68] Borges, C.; Barbosa,H.;Lemonge,A.A structural damage identification method based on genetic algorithm and vibrational data, International Journal for Numerical Methods in Engineering, 2007; Volume 69, pp. 2663-2686.

[69] Kouchmeshky, B.; Aquino, W.;Bongard,J.; Lipson, H. Co-evolutionary algorithm for structural damage identification using minimal physical testing, International Journal for Numerical Methods in Engineering, 2007; Volume 69, Issue No. 5, pp. 1085-1107.

[70] Meruane, V.; Heylen, W. Structural damage assessment under varying temperature conditions, Structural Health Monitoring, 2012, Volume 11, Issue No. 3, pp. 345-357.

[71] Kuang, K. S. C.;Maalej, M.; Quek, S. T.An Application of a Plastic Optical Fiber Sensor and Genetic Algorithm for Structural Health Monitoring, Journal of Intelligent Material Systems and Structures, 2006; Volume 17, Issue No. 5, pp. 361-379.

[72] Nag,A.;Mahapatra, D. R.;Gopalakrishnan, S. Identification of delamination in composite beams using spectral estimation and a genetic algorithm, Smart Mater. Struct., 2002; Volume 11, pp. 899-908.

[73] Khatir, S.; Belaidi, I,; Khatir, T.; Hamrani, A.; Zhou, YL.; Wahab, MA. Multiple damage detection in unidirectional graphite-epoxy composite beams using particle swarm optimization and genetic algorithm, MECHANIKA, 2017; Volume 23, Issue No. 4, pp.514-521.

[74] Santos, A.; Figueiredo, E.; Silva M.; Santos R.; Sales C.; Costa, J. C. W. A. Genetic-based EM algorithm to improve the robustness of Gaussian mixture models for damage detection in bridges, Struct. Control Health Monit., 2017; Volume 24, Issue No. 3.

[75] Cha, Y.-J.; Buyukozturk, O. Structural Damage Detection Using Modal Strain Energy and Hybrid Multiobjective Optimization, Computer-Aided Civil and Infrastructure Engineering, 2015; Volume 30,pp. 347-358.

[76] Zadeh, L. A. Fuzzy sets, Information and Control, 1965; Volume 8, Issue No. 3, pp. 338-353.

[77] Hajek, P.; Paris, J.; Shepherdson, J. The liar paradox and fuzzy logic, J. Symb. Logic, 2000; Volume 65, pp. 339-346.

[78] Raju, K.; Majumdar, A.Fuzzy functional dependencies and lossless join decomposition of fuzzy relational database systems, ACM Trans. Database Syst., 1988; Volume 13, Issue No. 32, pp. 129-166.

[79] Hajek, P.; Havranek, T.; Jirousek, R.Processing Uncertain Information in Expert Systems, CRC Press, Boca Raton, 1992.

[80] Juuso, E. K. Intelligent systems design with linguistic equations, 9th Workshop Fuzzy Control des GMA-FA, Dortmund, Germany, 1999; pp. 177196.

[81] Liu, X.; Ma, L.; Mathew, J. Machinery fault diagnosis based on fuzzy measure and fuzzy integral data fusion techniques, Mechanical Systems and Signal Processing, 2009; Volume 23, Issue No. 3, pp. 690-700.

[82] Rodríguez, P. V. J.; Arkkio, A.Detection of stator winding fault in induction motor using fuzzy logic, Applied Soft Computing, 2008; Volume 8, Issue No. 2, pp. 1112-1120.

[83] Sazonov, E. S.; Klinkhachorn, P.; Gangarao, H. V. S.; Halabe, U. B. Fuzzy Logic Expert System for Automated Damage Detection from Changes in Strain Energy Mode Shapes, Nondestructive Testing and Evaluation, 2002; Volume 18, Issue No. 1, pp. 1-20.

[84] Aljoumaa, H.; Soffker, D. Condition Monitoring and Classification Approach based on Fuzzy-Filtering, Proceedings of the World Congress on Engineering and Computer Science, San Francisco, USA, 2010.

[85] Reda Taha, M. M.; Lucero, J. Damage identification for structural health monitoring using fuzzy pattern recognition,Engineering Structures, 2005; Volume 27, Issue No. 12, pp. 1774-1783.

[86] Worden, K.; Delieu-Barton, J. M.An overview of intelligent fault detection in systems and structures, Structural Health Monitoring, 2004; Volume 3, pp. 85-98.

[87] Altunok, E.; Reda Taha, M. M.;Epp, D. S.; Mayes, R. L.; Baca, T. J. Damage Pattern Recognition for Structural Health Monitoring Using Fuzzy Similarity Prescription, Computer-Aided Civil and Infrastructure Engineering, 2006; Volume 21, pp. 549-560.

[88] Ettefagh, M.M.; Sadeghi, M.H.;Khanmohammadi, S.Structural Damage Detection, Using Fuzzy Classification and ARMA Parametric Modeling, Mech. \& Aerospace Eng. J., 2007; Volume 3, Issue No. 2, pp. 85-98.

[89] Yu, L.; Zhu, J-H.; Yu, L-L. Structural Damage Detection in a Truss Bridge Model Using Fuzzy Clustering and Measured FRF Data Reduced by Principal
Component Projection, Advances in Structural Engineering, 2013; Volume 16, Issue No. 1, pp. 207-217.

[90] Jiang, S-F.; Zhang, C-M.; Zhang, S. Two-stage structural damage detection using fuzzy neural networks and data fusion techniques, Expert Systems with Applications, 2011; Volume 38, pp. 511-519.

[91] Beena, P.; Ganguli, R. Structural damage detection using fuzzy cognitive maps and Hebbian learning, Applied Soft Computing, 2011; Volume 11, pp. 1014-1020.

[92] Liu, Z.; Zhou, Q; Chi, Q.; Zhang, Y.; Chen, Y.; Qi, S. Structural Damage Detection Based on Semi-Supervised Fuzzy C-means Clustering, The 9th International Conference on Computer Science \& Education (ICCSE 2014), 2014.

[93] Irwansyah,E.; Hartati, S.; Hartono. Three-stage Fuzzy Rule-Based Model for Earthquake Non-Engineered Building House Damage Hazard Determination, JACIII, 2017; Volume 21, Issue No. 7, pp. 1298-1311.

[94] Janalipour, M.; Mohammadzadeh, A. Building Damage Detection Using Object-Based Image Analysis and ANFIS From High-Resolution Image (Case Study: BAM Earthquake, Iran), IEEE Journal of Selected Topics in Applied Earth Observations and Remote Sensing, 2016; Volume 9, Issue No. 5, pp. 1937-1945.

[95] Ye, X.; Qin, Q.; Liu, M.; Wang, J.; Wang, J. Building damage detection from post-quake remote sensing image based on fuzzy reasoning, IEEE Geoscience and Remote Sensing Symposium, Quebec City, QC, 2014, pp. 529-532.

[96] Rumelhart,D. E. .; McClelland, J. L.; the PDP Research Group, Parallel Distributed Processing: Explorations in the Microstructure of Cognition, Volume I: Foundations, MIT Press, Cambridge, MA, 1986.

[97] Wu, X. .; Ghaboussi, J.; Garrett Jr., J.H. Use of neural networks in detection of structural damage, Computers \& Structures, 1992; Volume 42, Issue No. 4, pp. 649-659.

[98] Zhao, J.; Ivan, J. N.; DeWolf, J. T. Structural Damage Detection using Artificial Neural Networks, Journal of Infrastructure Systems, 1998; Volume 4, Issue No. 3, pp. 93-101.

[99] Rhim, J.; Lee, S.W. A neural network approach for damage detection and identification of structures, Computational Mechanics, 1995; Volume 16, Issue No. 6, pp. 437-443.

[100]Pandey, P. C.; Barai, S. V. Multilayer Perceptron in Damage Detection of Bridge Structures, Computers \& Structures, 1995; Volume 54, Issue No. 4, pp. 597-608.

[101]Elkordy, M. F.; Chang, K. C.; Lee, G. C. Neural networks trained by analytically simulated damage states, Journal of Computers in Civil Engineering, 1993; Volume 7, Issue No. 2, pp. 130-145.

[102] Hung, S-L.; Kao, C. Y. Structural damage detection using the optimal weights of the approximating artificial neural networks, Earthquake Engineering \& Structural Dynamics, 2002; Volume 31, pp. 217-234.

[103] Wu, Z.; Xu, B.; Yokoyama, K. Decentralized Parametric Damage Detection Based on Neural Networks, Computer-Aided Civil and Infrastructure Engineering, 2002; Volume 17, pp. 175-184.

[104] Suresh, S.; Omkar, S. N.; Ganguli, R.; Mani, V. Identification of crack location and depth in a cantilever beam using a modular neural network approach, Smart Materials and Structures, 2004; Volume 13, pp. 907-915.

[105] Sahin, M.; Shenoi, R.A. Quantification and localization of damage in beamlike structures by using artificial neural networks with experimental validation, Engineering Structures, 2003; Volume 25, pp. 1785-1802.

[106]Lee, J. J.; Lee, J. W.; Yi, J. H.; Yun, C. B.; Jung, H. Y. Neural networks-based damage detection for bridges considering errors in baseline finite element models, Journal of Sound and Vibration, 2005; Volume 280, pp. 555-578.

[107] Mehrjoo, M.; Khaji, N.; Moharrami, H.; Bahreininejad, A. Damage detection of truss bridge joints using Artificial Neural Networks, Expert Systems with Applications, 2008; Volume 35, pp. 1122-1131.

[108] Kao, C. Y.; Hung, S-L. Detection of structural damage via free vibration responses generated by approximating artificial neural networks, Computers and Structures, 2003; Volume 81, pp. 2631-2644.

[109]Bakhary, N.; Hao, H.; Deeks, A. J. Structure Damage Detection Using Neural Network with Multi-Stage Substructuring, Advances in Structural Engineering, 2010; Volume 13, Issue No. 1, pp. 95-110.

[110] Yeung, W.T.; Smith, J.W. Damage detection in bridges using neural networks for pattern recognition of vibration signatures, Engineering Structures, 2005; Volume 27, pp. 685-698.

[111]111. Nazarko, P.; Ziemiański, L. Application of artificial neural networks in the damage identification of structural elements, Computer Assisted Mechanics and Engineering Sciences, 2011; Volume 18, pp. 175-189.

[112] Haryanto, I.; Setiawan, D.; Budiyono, A. Structural Damage Detection Using Randomized Trained Neural Networks, Intelligent Unmanned Systems: Theory and Applications, 2009; Volume 192, pp. 245-255.

[113] Bakhary, N.; Hao, H.; Deeks, A. J. Damage detection using artificial neural network with consideration of uncertainties, Engineering Structures, 2007; Volume 29, pp. 2806-2815. 
[114]Chang, C. C.; Chang, T. Y. P.; Xu, Y. G. Structural Damage Detection Using an Iterative Neural Network, Journal of Intelligent Material Systems and Structures, 2000; Volume 11, pp. 32-42.

[115] Chatterjee, S.; Sarkar, S.; Hore, S.; Dey, N.; Ashour, A.S.; Balas, V.E. Particle swarm optimization trained neural network for structural failure prediction of multistoried RC buildings. Neural Comput. Appl., 2017; Volume 28, Issue No 8.

[116]Nia, K. R.; Mori, G. Building Damage Assessment Using Deep Learning and Ground-Level Image Data, 14th Conference on Computer and Robot Vision (CRV), 2017; pp.95-102.

[117] Kourehli, S.S. Damage Assessment in Structures Using Incomplete Modal Data and Artificial Neural Network, International Journal of Structural Stability and Dynamics, 2015; 17 pages.

[118] Abdeljaber, O.; Avci, O.; Kiranyaz, S.; Gabbouj, M.; Inman, D. J. Real-time vibration-based structural damage detection using one-dimensional convolutional neural networks, Journal of Sound and Vibration, 2017; Volume 388, pp. 154-170.

[119] Hefny, H. A.; Bahnasawi, A. A.; Abdel Wahab, A. H.; Shaheen, S. I. Logical radial basis function networks a hybrid intelligent model for function approximation, Advances in Engineering Software, 1999; Volume 30, pp. 407-417.

[120]Zheng, S-J.; Li, Z-Q.; Wang, H-T.; A genetic fuzzy radial basis function neural network for structural health monitoring of composite laminated beams, Expert Systems with Applications, 2011; Volume 38, pp. 1183711842.

[121] Aydin, K; Kisi, O. Damage detection in structural beam elements using hybrid neuro fuzzy systems, Smart Structures and Systems, 2015; Volume 16, Issue No. 6, pp.1107-1132.

[122] Izadi, M.; Mohammadzadeh, A.; Haghighattalab, A. A New Neuro-Fuzzy Approach for Post-earthquake Road Damage Assessment Using GA and SVM Classification from QuickBird Satellite Images, Journal of the Indian Society of Remote Sensing, 2017; pp. 1-13.

[123]Janalipour, M.; Mohammadzadeh, A. A Fuzzy-GA Based Decision Making System for Detecting Damaged Buildings from High-Spatial Resolution Optical Images, Remote Sens. 2017; Volume 9, Issue No. 4.

[124] Brownjohn, J. M. W. Structural health monitoring of civil infrastructure, Phil. Trans. R. Soc. A, 2007; Volume 365, pp. 589-622. 